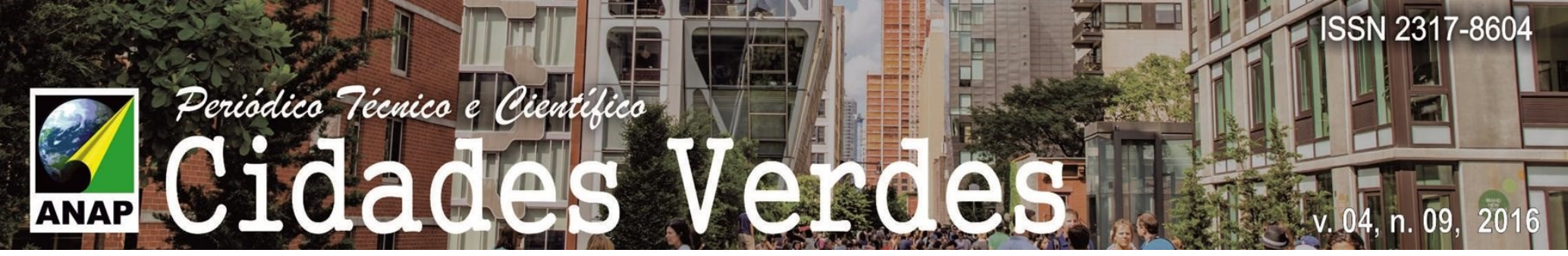

\title{
ZONEAMENTO AMBIENTAL DE PUERTO LIBERTADOR-CÓRDOBA COMO INSUMO PARA A DETERMINAÇÃO DA CAPACIDADE DE RECEBER A MINERAÇÃO.
}

\author{
Dánika Andrea Castillo Ospina ${ }^{1}$
}

Esteban José Esquivel Gómez²

Viviana Cecilia Soto Barrera ${ }^{3}$

\begin{abstract}
Resumo
O município de Puerto Libertador, localizado no Departamento de Córdoba, Colômbia, é um território que há muitos anos atrás tem sido fonte de recursos minerais de grande interesse econômico como o ouro, o carvão, entre outros. A mineração como uma das principais atividades econômicas, na maioria dos casos, tem sido realizada de forma ilegal e em locais de grande interesse ambiental, gerando diversos conflitos entre o uso do solo e do subsolo e graves problemas de polução. Portanto, o objetivo deste estudo foi realizar o zoneamento ambiental do município como insumo para a determinação da capacidade de receber a atividade mineira. Este foi obtido pela identificação das zonas de exclusão e restrição para a mineração, tendo em conta o marco legal do sector mineiro-ambiental, do que resultou que $37,4 \%$ (61.712 ha) do município tem restrição para a mineração e 18,41 \% (30.404 ha) do território é proibida a mineração. A união de ambas áreas possibilitou a delimitação das zonas de conservação e proteção ambiental para a mineração, gerando um área total de $89.619,97$ ha que corresponde um 54,29\% do município, todo feito em um marco de sistema de informação geográfica.
\end{abstract}

Palavras-chave: Zoneamento ambiental, mineração, sistemas de informação geográfica.

\section{ENVIROMENTAL ZONING OF PUERTO LIBERTADOR-CÓRDOBA AS INPUT FOR DETERMINATION OF MINING RECEPTION CAPACITY}

\footnotetext{
Abstract

The town of Puerto Libertador, located in Cordoba, Colombia, is a territory that, for many years, has been the root of mineral resources of great economic interest such as gold, coal, and others. However, mining is one principal economic activity and in most cases, has been conducted illegally and in places of great environmental interest, causing in this way conflicts between soil and subsoil use, as well as severe pollution problems. Perform the environmental zoning as

${ }^{1}$ Engenheira ambiental, bolsista de iniciação científica UNICOR, Universidade de Córdoba Colômbia, dnkcastillo@gmail.com.

${ }^{2}$ Engenheiro ambiental, bolsista de iniciação científica UNICOR, Universidade de Córdoba Colômbia, esteban_jose_93@hotmail.com.

${ }^{3}$ Engenheira ambiental e sanitária, Universidade da Salle, Mestre em Geografia, Especialista em Gestão de Negócios e Professora do departamento de engenharia ambiental Universidade de Córdoba, Colômbia.
} 


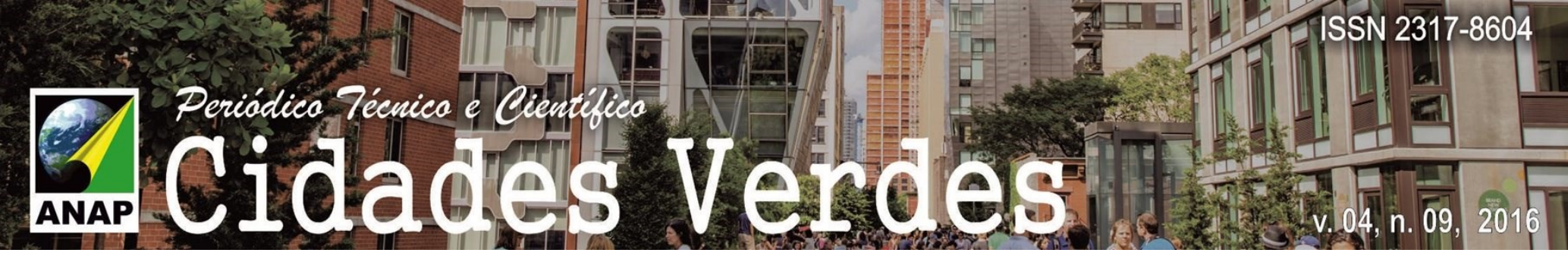

input of mining reception capacity in the town of Puerto Libertador was the main fundamental purpose of this research. For this zoning was needed the identification of restriction and exclusion areas for mining. This identification generated that 37,4\% (61.712 ha) are restriction areas and 18,41\% (30. $404 \mathrm{ha}$ ) are exclusion areas. These zones produced the environmental protection areas for mining activity which GIS (Geographic Information System) was applied.

Key words: environmental zoning, mining activity, GIS

\title{
ZONIFICACIÓN AMBIENTAL DE PUERTO LIBERTADOR-CÓRDOBA COMO INSUMO PARA LA DETERMINACIÓN DE LA CAPACIDAD DE ACOGIDA PARA LA MINERÍA.
}

\begin{abstract}
Resumen
El municipio de Puerto Libertador, localizado en el Departamento de Córdoba, Colombia, es un territorio que desde hace muchos años ha sido fuente de recursos minerales de gran interés económico como son el oro, el carbón, entre otros. La minería como una de las principales actividades económicas, en la mayoría de los casos, se ha venido realizando de manera ilegal y en sitios de gran interés ambiental, generando así conflictos entre el uso del suelo y el subsuelo y severos problemas de contaminación. Por tanto el objetivo de este estudio fue realizar la zonificación ambiental del municipio como insumo para la determinación de la capacidad de acogida para la minería, esto se obtuvo gracias a la identificación de las zonas de exclusión y de restricción para la extracción minera de acuerdo al marco legal del sector minero-ambiental, de esta identificación se obtuvo que el 37,4\% (61.712 ha) del municipio tiene restricción para la minería y en el 18,41\% (30. 404 ha) del territorio se prohíbe esta actividad. La unión de ambas áreas permitió la delimitación de las zonas de conservación e protección ambiental generando un área total del 89619,97 ha que corresponde un 54,29\%, todo hecho a través del aplicación de sistemas de información geográfica.
\end{abstract}

Palabras Clave: zonificación ambiental, minería, sistemas de información geográfica.

\section{INTRODUÇÃO}

O planejamento territorial é a localização mais adequada, dentro de uma determinada área geográfica, das diferentes atividades humanas com base nos impactos ambientais gerados por elas (BARETTINO, 2002), por isso é uma ideia universalmente aceitada que assegurar o desenvolvimento das várias atividades humanas ocorrem de forma equilibrada com a proteção e conservação do meio ambiente, ele passa por um planejamento adequado sobre o território (BARETTINO et al., 1994).

A mineração, uma das atividades humanas dedicadas à extração de Georrecursos para abastecer a população de matérias-primas, deve ser obrigatoriamente integrado com o planejamento do uso da terra, mas para que isso seja alcançado é necessário realizar um processo de zoneamento mineiro-ambiental, de acordo ARRANZ (2008) visa a localização das explorações e as estruturas de 


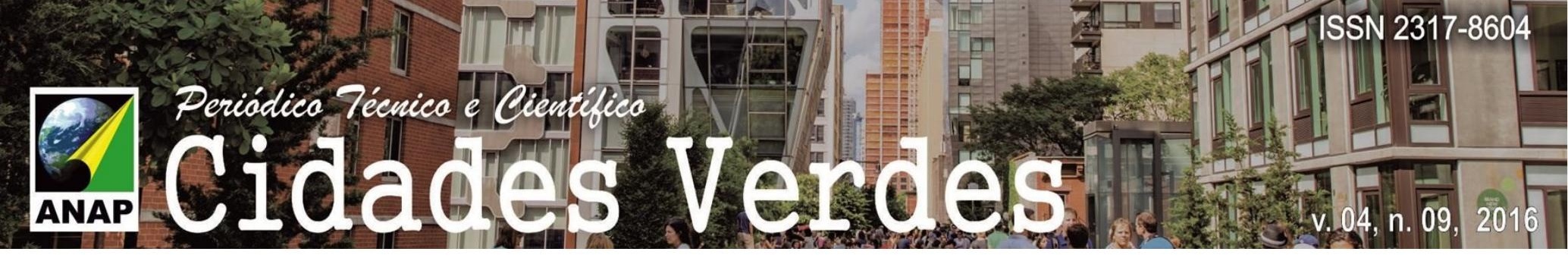

\section{Marco legal}

Os regulamentos aplicáveis neste estudo estão relacionados com as políticas, leis, decretos, códigos e regulamentos que regem o setor do ambiente e setor de mineração, assim como outros que pela sua conexão fazem parte dos temas de Zoneamento, Planejamento e Gestão ambiental e mineração. Da mesma forma, destaca-se o componente de zoneamento enquanto identificam-se os regulamentos que preveem restrições e proibições de terras para mineração, com o objetivo primordial de priorizar a gestão ambiental e desenvolvimento de comunidades ancestrais. A Figura 1 mostra o atual quadro jurídico relacionado à mineração na Colômbia.

Figura 1 - Atual quadro jurídico relacionado ao setor ambiental e de mineração na Colômbia.
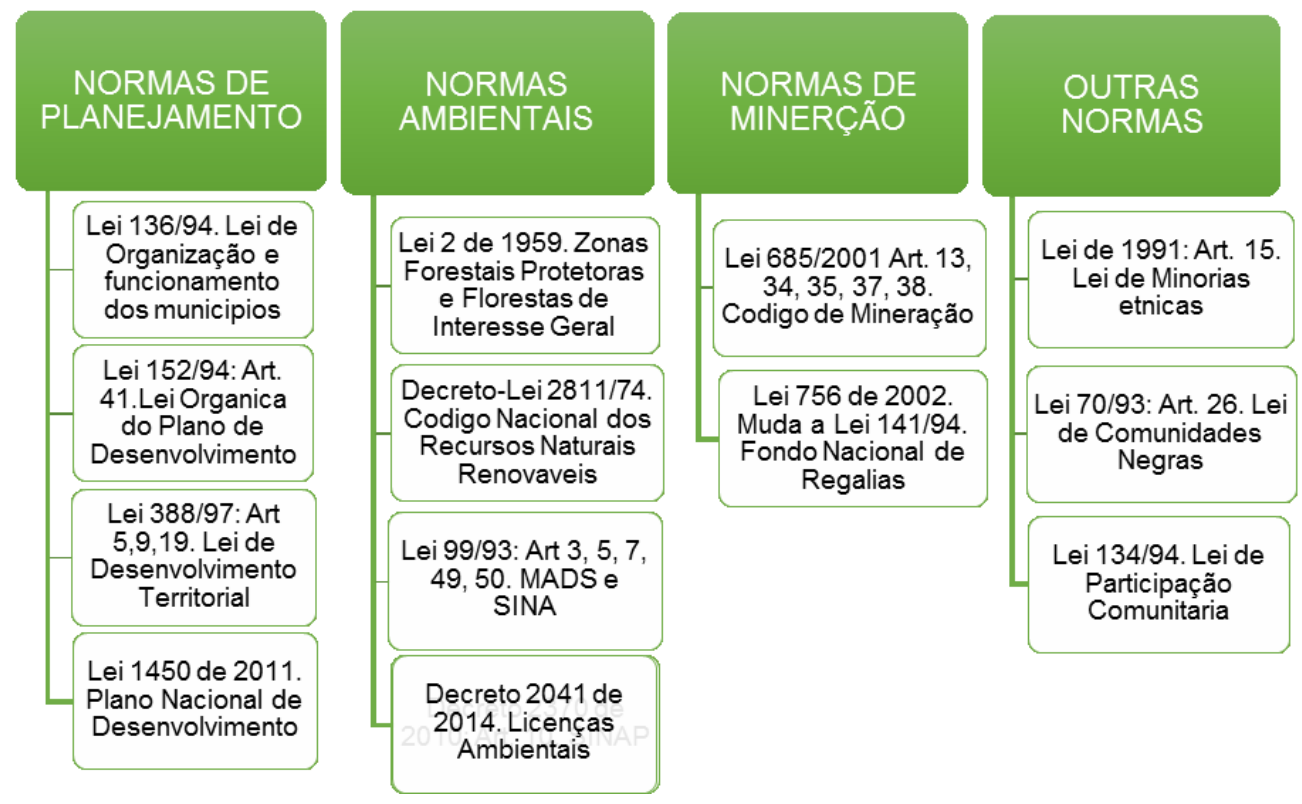

Fonte: AUTORES

\section{METODOLOGIA}




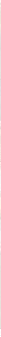

O desenvolvimento desta pesquisa consistiu em duas fases: caracterização territorial e delimitação de áreas de proteção ambiental e conservação. No quadro (Figura 2) seguinte pode-se ver claramente como foi o processo:

Figura 2 - Fases para o zoneamento ambiental
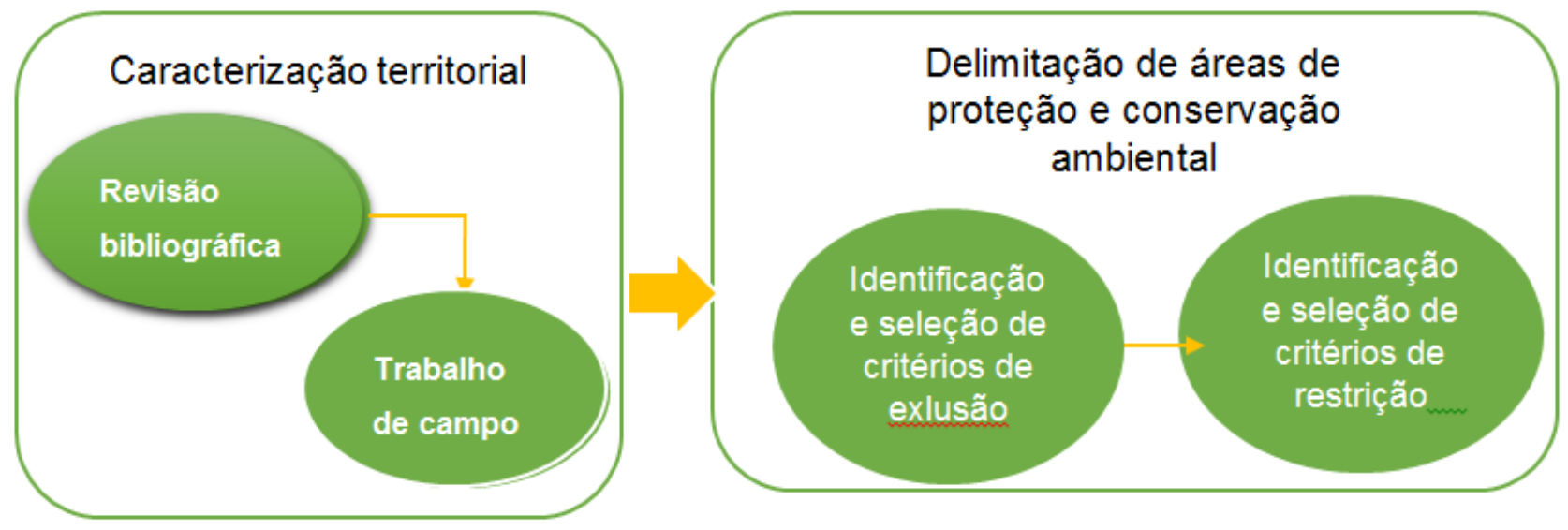

Fonte: AUTORES, 2015

A caracterização territorial compreende duas partes: revisão e análise da informação existente, onde se copilou toda a informação secundaria disponível atualizada para o município de Puerto Libertador das diferentes instituições dos níveis nacionais, departamentais e locais que estão relacionados com a mineração na Colômbia, e o trabalho de campo, que se concentrou em informações primárias de campo com base em inspeções feitas sobre os pontos de mineração no município (ativa ou inativa) e entrevistas destinadas a entidades públicas ou privadas relacionadas com mineração no município. As características que foram tidas em conta foram as condições físicas, bióticas e socioeconômicas necessárias para delimitar os critérios de exclusão e restrições para a mineração.

A segunda fase, chamada a delimitação das áreas de proteção ambiental e conservação foram realizadas de acordo com os regramentos estabelecidos para o setor minero-ambiental na Colômbia. Para o efeito, considerou-se que as zonas de exclusão são aquelas áreas proibidas para a mineração por razões ecológicas, sociais e / ou legais e das zonas de restrição são áreas onde o desenvolvimento da atividade de mineração é restrito, mas não se impede.

Para alcançar este zoneamento desenvolveu-se um modelo cartográfico cujas entradas foram obtidas a partir das informações coletadas durante a primeira fase. A sua aplicação foi feita num ambiente Sistema de Informação geográfica-SIG (Arcgis 10.1), onde a união das camadas de síntese de exclusão e restrição gerou o mapa de áreas de conservação e proteção ambiental para a 


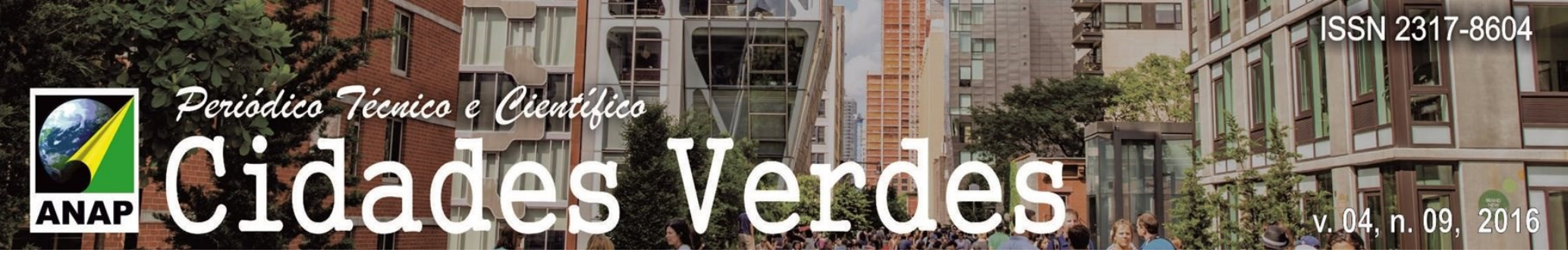

mineração de Puerto Libertador. Os produtos desta pesquisa foram trabalhados numa escala de 1:100.000.

\section{RESULTADOS}

\section{Caracterização territorial}

Nesta fase, teve-se em conta as seguintes características

Caracterização Físico-biótica: Do recurso solo, foram consideradas no estudo as condições das coberturas do solo. A tabela 1 lista os tipos de cobertura presentes na área de estudo como também seu porcentagem dentro do município. Estas coberturas se mostram no mapa 1.

Tabela 1 - Coberturas terrestres em Puerto libertador

\begin{tabular}{|c|c|c|}
\hline $\begin{array}{l}\text { Cobertura } \\
\text { terrestre }\end{array}$ & Descrição & \% Municipio \\
\hline Centro poblado & Superfícies de assentos de populações (urbanas ou rurais) & 0,059 \\
\hline $\begin{array}{l}\text { Áreas de } \\
\text { mineração }\end{array}$ & Superfície de mineração de materiais & 0,120 \\
\hline Restolhos & $\begin{array}{l}\text { Áreas com vegetação constituída por uma mistura de gramíneas com } \\
\text { restolho de diferentes tamanhos e consistência }\end{array}$ & 22,53 \\
\hline Vegetação baixa & $\begin{array}{c}\text { Áreas cobertas com vegetação adaptada a solos que permanecem sob } \\
\text { a água um longo período do ano durante a estação chuvosa. }\end{array}$ & 0,13 \\
\hline $\begin{array}{l}\text { Pastos } \\
\text { melhoradoss }\end{array}$ & Pastagens que foram plantados como uma monocultura & 8,54 \\
\hline $\begin{array}{l}\text { Pastos de } \\
\text { restolho }\end{array}$ & $\begin{array}{l}\text { Áreas estão restabelecidas devido ao abandono das atividades } \\
\text { agrícolas e pecuários, entre outros. }\end{array}$ & 25,81 \\
\hline Culturas & $\begin{array}{l}\text { Superfícies cultivadas pelos sistemas tradicionais e usinadas incluindo } \\
\text { também áreas com gramíneas. }\end{array}$ & 0,71 \\
\hline $\begin{array}{l}\text { Floresta } \\
\text { secundária }\end{array}$ & $\begin{array}{l}\text { Está representado pela floresta que está desenvolvendo-se e está } \\
\text { localizado num estágio intermediário de sucessão entre floresta } \\
\text { primária e restolho. }\end{array}$ & 27,36 \\
\hline $\begin{array}{l}\text { Floresta } \\
\text { primária }\end{array}$ & $\begin{array}{l}\text { As áreas com cobertura de árvores de diferentes estratos e associações } \\
\text { de plantas altamente complexos, com pouca intervenção ou sem } \\
\text { intervenção e ainda conservam a sua estrutura original. }\end{array}$ & 14,26 \\
\hline Corpos de água & Composto por corpos de água doce (rios, pântanos e lagos) & 0,39 \\
\hline
\end{tabular}

Fonte: Baseado em Corporação autônoma regional dos Vales do Sinú y São Jorge- CVS, 2005.

Respeito ao recurso hídrico, Puerto Libertador é uma cidade com abundancia hídrica devido a várias correntes superficiais que passam através do seu território. As principais correntes superficiais do município tendo em conta o Plano de desenvolvimento municipal-PDM (2012 - 


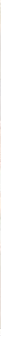

2015) e estudos feitos por AMBIENTEC (1986) são: Rio San Pedro, Rio sujo, Quebrada As Claras entre outras. A forma de distribuição dos corpos hídricos pode-se ver no mapa 2.

O Parque Nacional Natural Paramillo é o principal recurso biótico do município e está localizado ao norte da faixa ocidental nos departamentos de Córdoba e Antioquia. Do território total do parque, o departamento de Córdoba é responsável por 70\% (322 mil ha) e Puerto Libertador atribule-se aproximadamente 50.000 ha.

Conforme descrito no Esquema de Ordenamento Territorial 2005-2017 - EOT (Prefeitura de Puerto Libertador, 2005), a importância ambiental desta área protegida é que ela está localizada no cinturão da floresta tropical do Equador, é por isso que numa primeira fase, as suas três montanhas desempenham um papel crucial no processo de produção de chuvas em toda a área, com o surgimento destas florestas de nuvens, se tornam em ecossistemas reguladores climáticos. Em segundo lugar, a sua diversidade paisagística causada pelo gradiente de altitude, coleta diferentes ecossistemas desde paramos até florestas úmidas em planícies de inundação. Em terceiro lugar, considera-se a quarta estrela fluvial da Colômbia, já que estão os nascentes dos rios Sinú e San Jorge. Também, está incluído na área de endemismo de aves, o que o classifica como um lugar de alto endemismo e prioridade para a pesquisa e conservação em toda a América do Sul. 


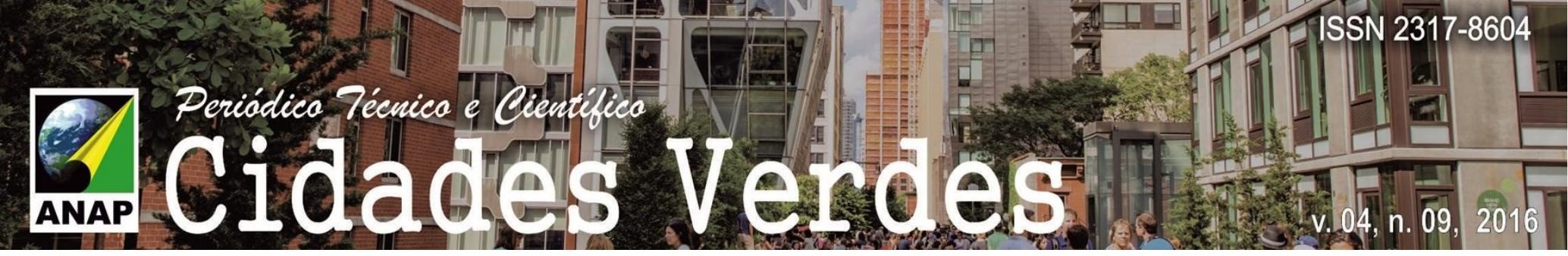

Mapa 1- Recurso Hídrico em Puerto Libertador

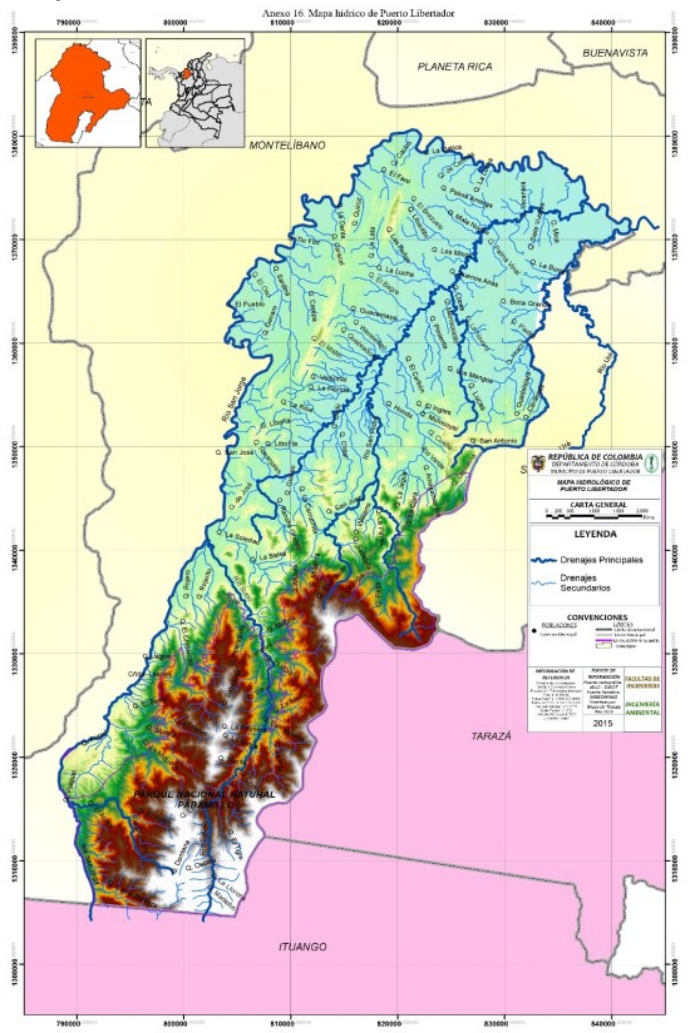

Mapa 2- Coberturas terrestres em Puerto Libertador

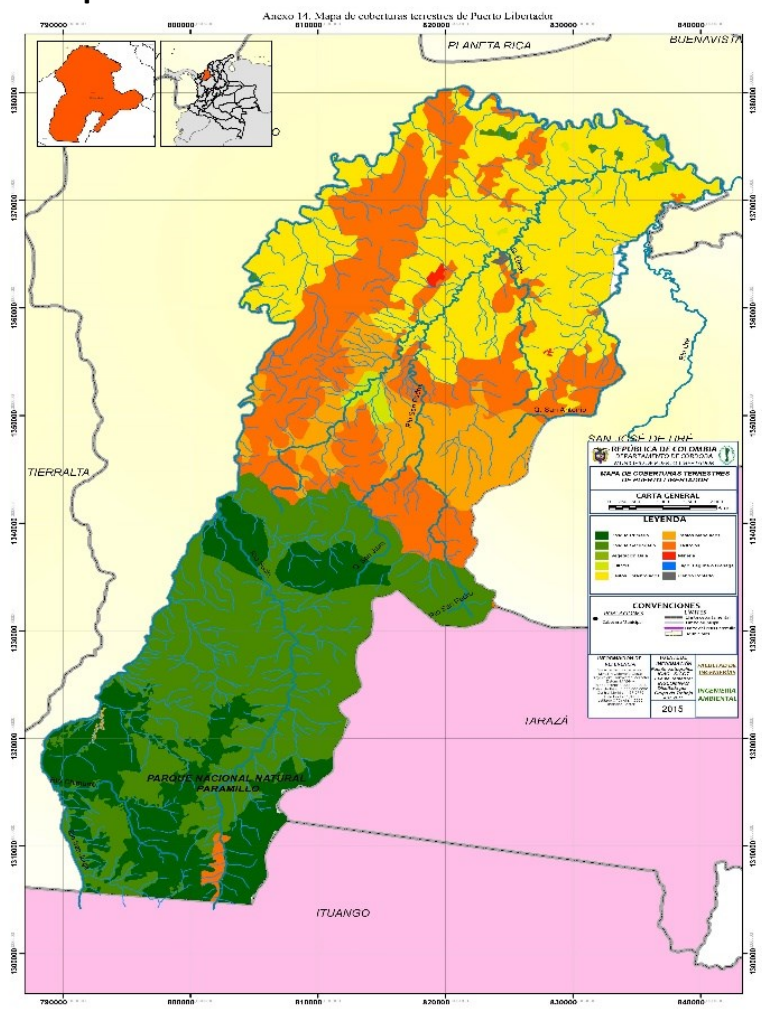

Fonte: Adaptado de CVS, 2005.

Fonte: Adaptado de CVS, 2005.

Caracterização socioeconômica: Nesta esfera, é de destacar a distribuição das atividades económicas no município, sendo a mineração uma das cinco principais atividades para os moradores de acordo à FUNDAÇÃO SAN ISIDRO et al. (2012)

Um dos componentes sociais que dão um grau de particularidade do território é a presença de grupos étnicos, comunidades indígenas, destacando os seguintes:

Zenú: Este grupo tem uma população média de $5 \%$ da população total do município (município de Puerto Libertador 2012). Eles foram agrupados em pequenos enclaves de comunidades que estão localizadas nos distritos de Juan Jose, San Juan e Rio Verde. Principalmente eles trabalham na agricultura, pesca e artesanato, mas não têm assentamentos registrados.

Embera Katio: Eles representam 10\% do total da população de Puerto Libertador (Puerto Libertador 2012). Este grupo fica no sul do município, em áreas de selva e margens de rios San Pedro e Ure e também nos distritos de Pica Pica, Juan Jose, Belém e Carepa. Não obstante, este grupo tem uma área legalmente constituída (Resolução 010 de 1885 emitida pelo Instituto 


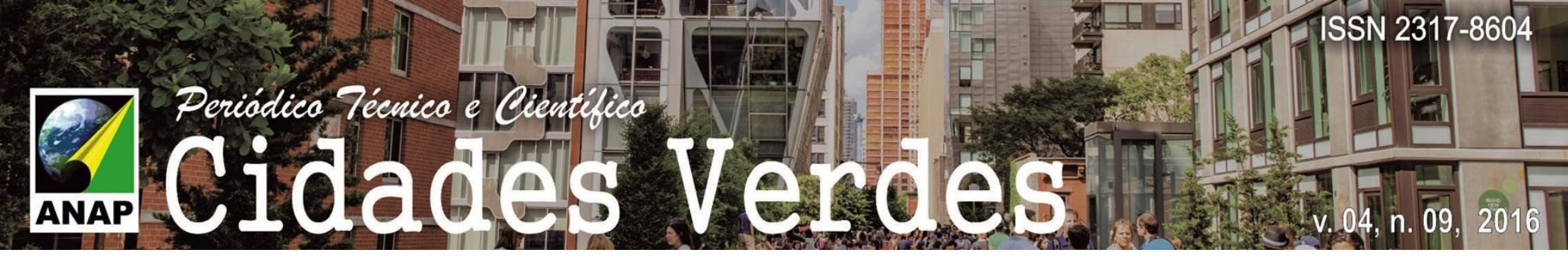

Colombiano de Reforma Agrária INCORA), que ocupa uma área no município de 2.808,81 ha, muitas comunidades que a compõem estão assentadas em outras locais.

Uma prova da riqueza do município em recursos minerais e o interesse por parte da população para adquirir direito para realizar a mineração legalmente, é a outorga de títulos mineiros, e a solicitude de títulos. A seguir se mostram como manifestam-se no município:

Títulos mineiros. É denominado assim à aquisição preliminar dada ao minerário para ter o direito de explorar e explotar em uma jazida, outorgado pela Agencia Nacional de mineração-ANM. Na atualização do registo de mineração de 29 de Janeiro, 2014 de esta agencia, Puerto Libertador tem um recorde de 36 títulos mineiros, correspondendo uma área total de 55,838.03 ha. Assim 33,82\% do território tem direito para a remoção de algum mineral. Além disso, nos gráfico 1 e 2 mostram que o carvão é o recurso com mais títulos mineiros tendo um total de 37,341.808 ha tituladas.

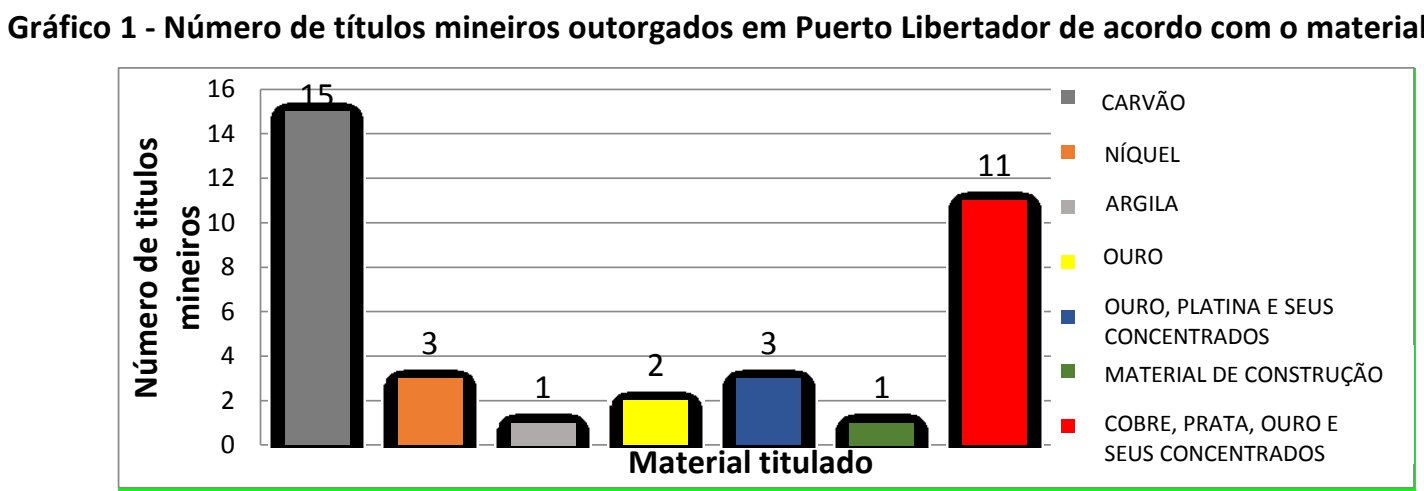

Fonte: Baseado em ANM, 2014.

Solicitações de títulos mineiros. Até janeiro de 2014, a ANM informou 57 solicitações de diferentes materiais no município. A área total solicitada foi $76,834.655$ ha, o que corresponde ao $46,54 \%$ do território. Note-se que $8.294,18$ ha da área de solicitação para mineração estão dentro do Parque Nacional Natural Paramillo.

Gráfico 2 - Total de hectares tituladas para cada material em Puerto Libertador

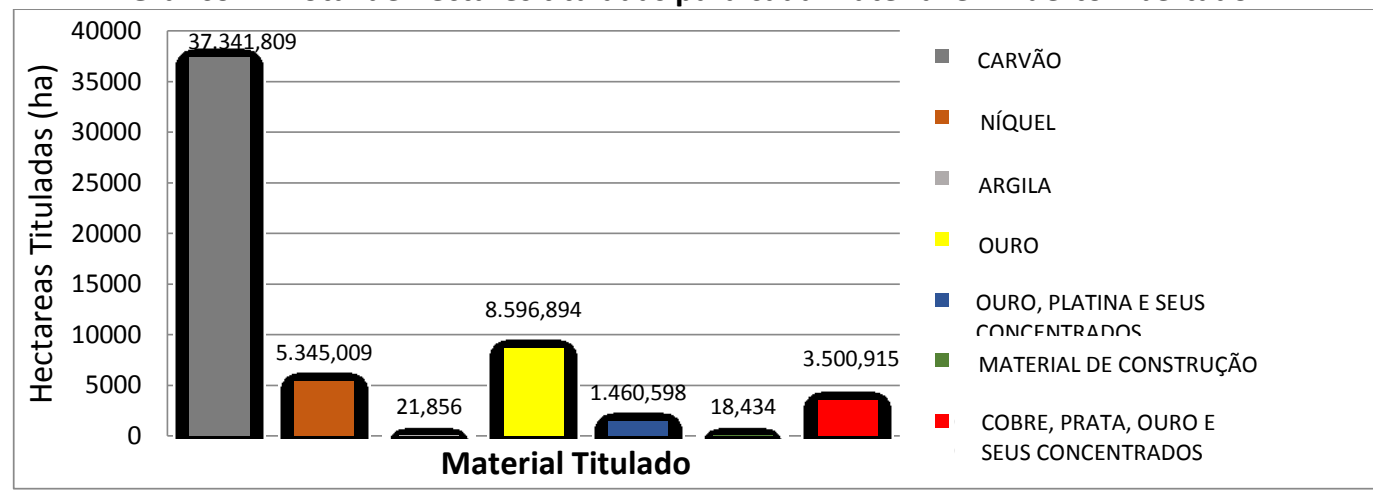

Fonte: Baseado em ANM, 2014. 


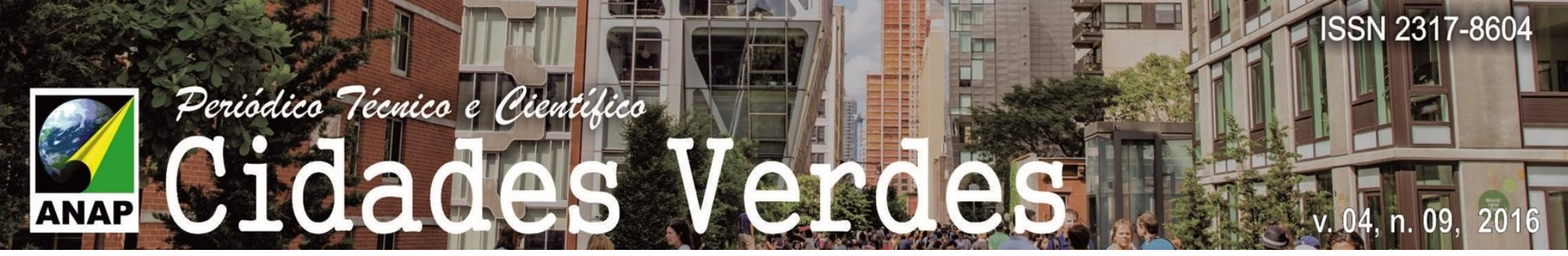

A localização no território das diferentes solicitações de mineração pode ser visto no mapa 3 . Além disso, nos gráficos 3 e 4 mostra-se que o cobre, metais preciosos, molibdénio e os seus concentrados são conjunto dos materiais mais solicitados, para os quais corresponde-Ihe cerca de $50,623.423$ ha.

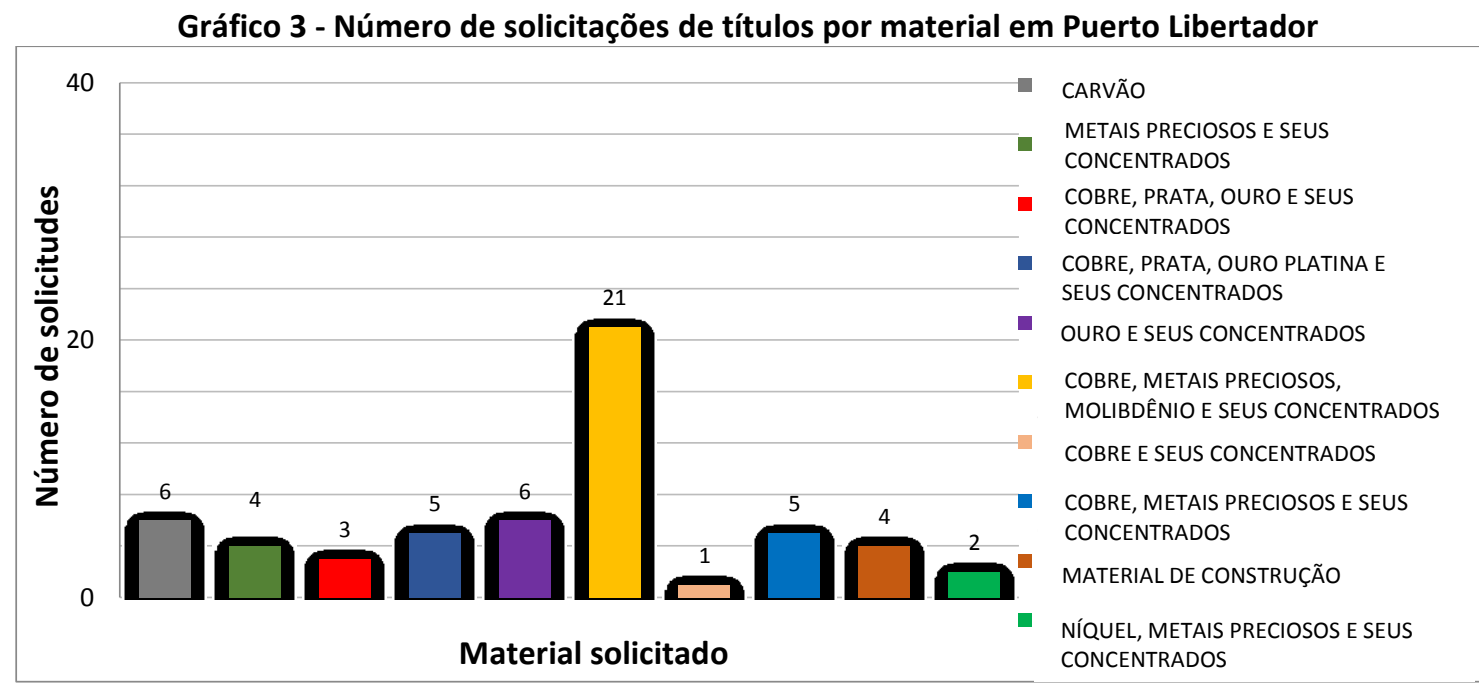

Fonte: Baseado em ANM, 2014.

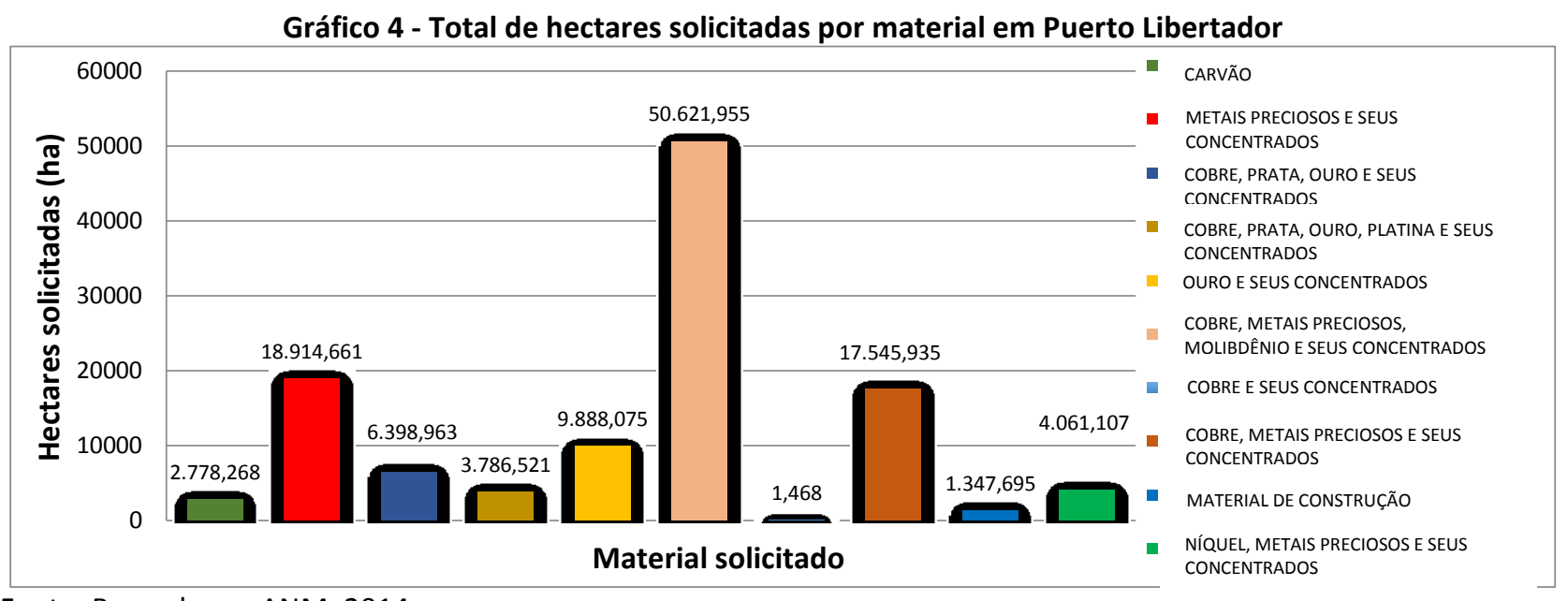

Fonte: Baseado em ANM, 2014.

Solicitações de legalização de mineração de feito (Lei 1382 de 2010): No cadastro atualizado de mineração de 29 de Janeiro, de 2014, a ANM informou 13 pedidos de legalização de mineração de feito em Puerto Libertador. A área total correspondente a esses pedidos é 16.336,98 ha, o que corresponde a 9,89\% do município.

Nos gráficos 5 e 6 mostra-se que os minerais de ouro e os seus concentrados são as solicitações mais elevados, num total de 10.020 ha. 


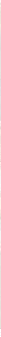

Mapa 3 - Titulos mineiros em Puerto Libertador.

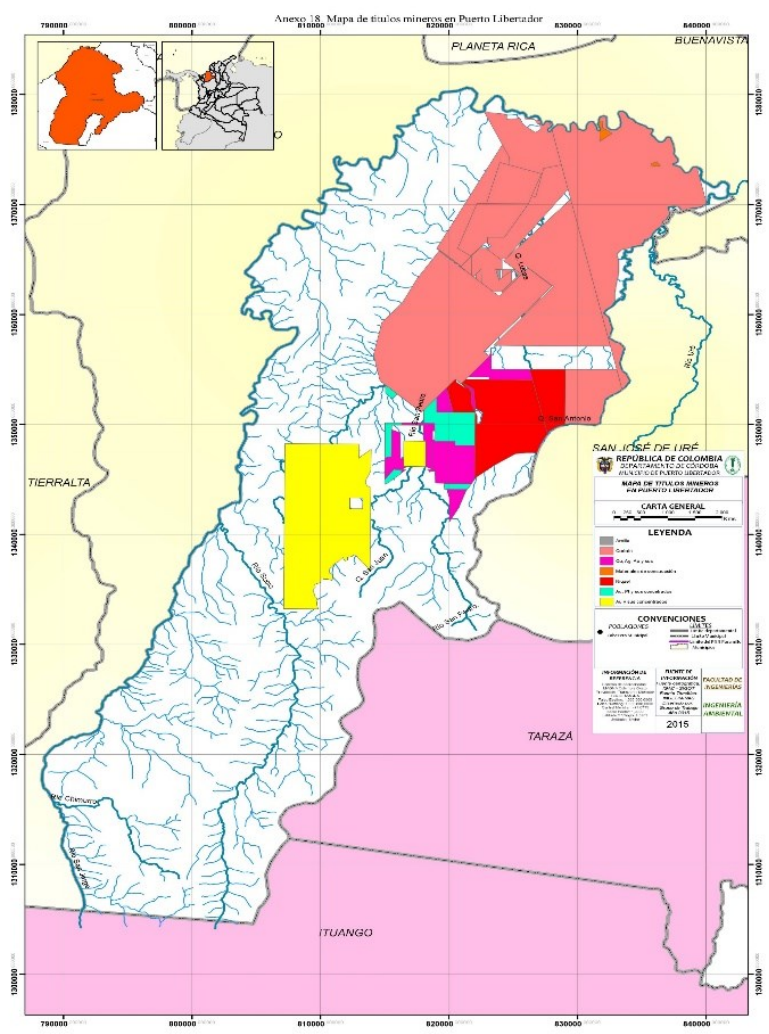

Fonte: Adaptado de ANM, 2014.
Mapa 4 - Solicitudes de titulos mineiros em puerto Libertador.

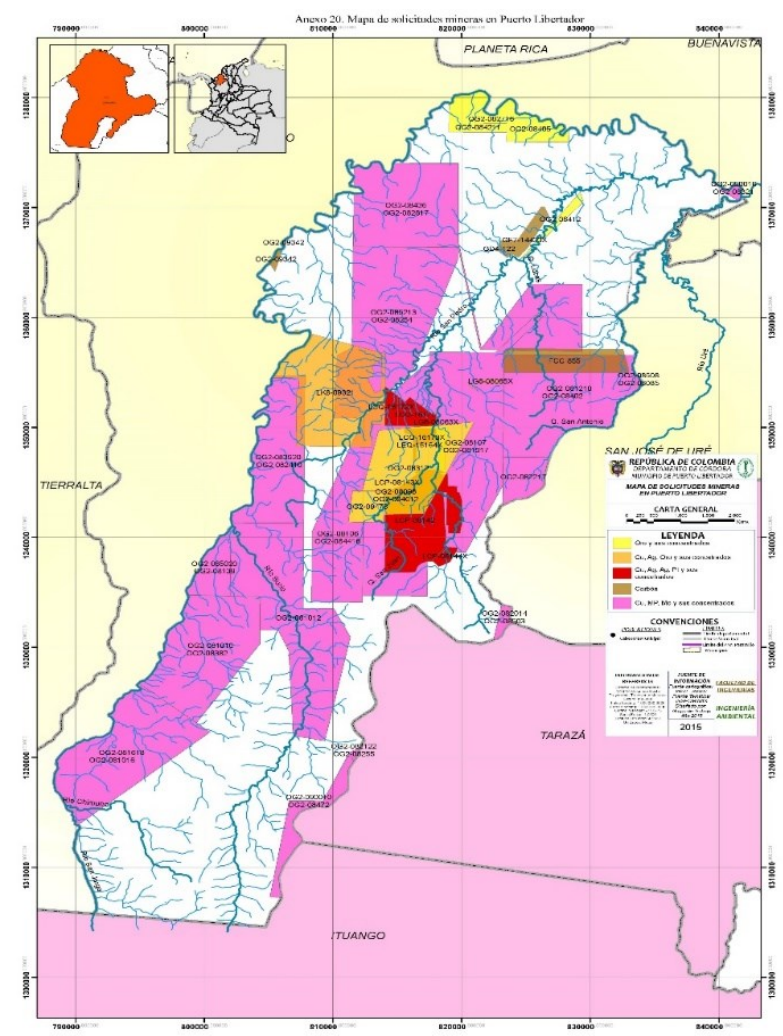

Fonte: Adaptado de ANM, 2014. 


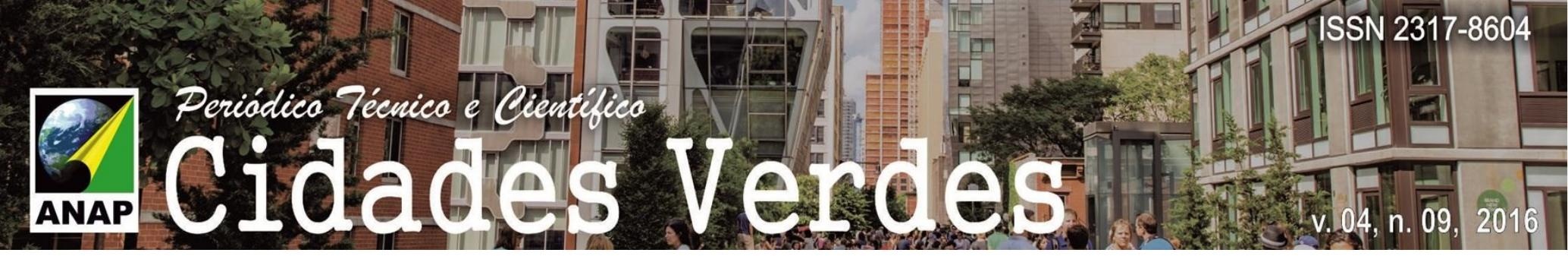

Mapa 5 - Solicitudes para legalização para mineração de feito por material em Puerto Libertador

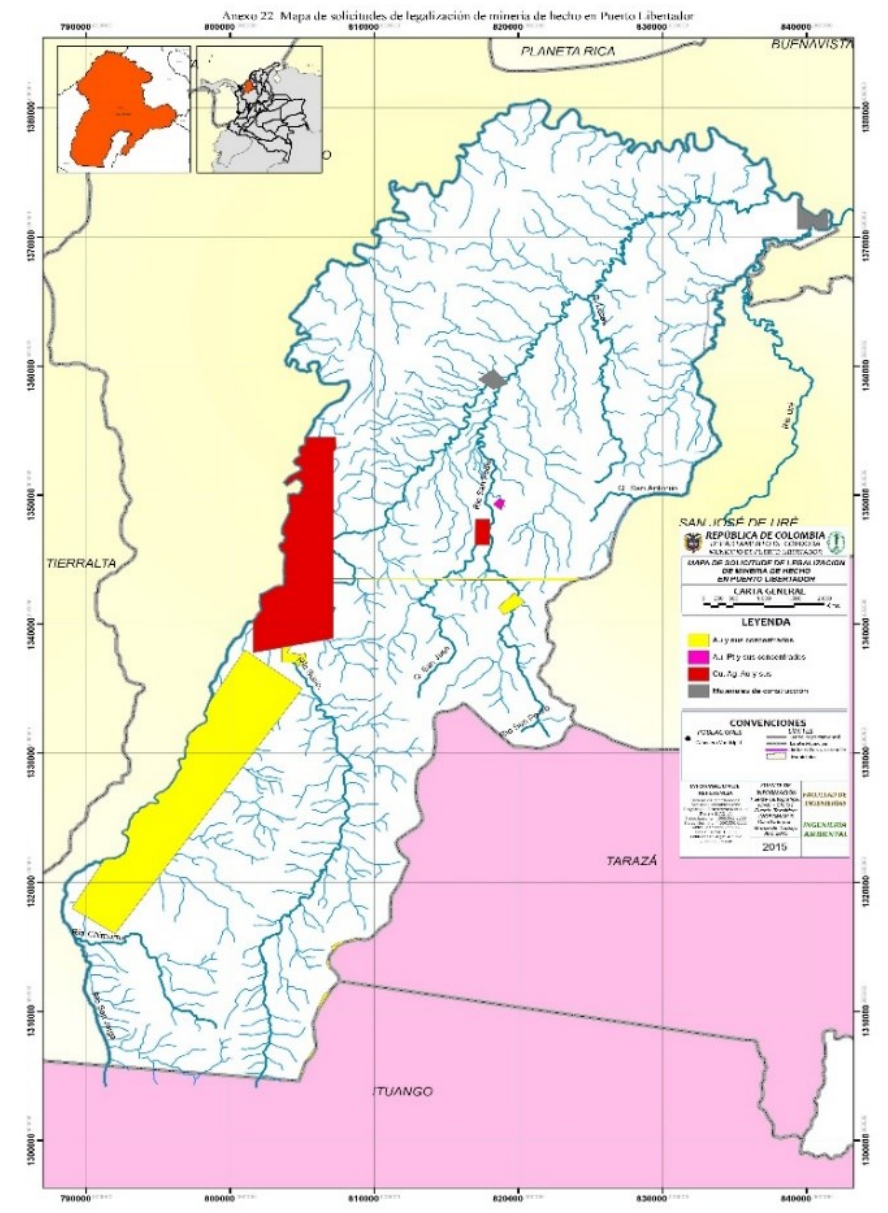

Fonte: Adaptado de ANM, 2014.

\section{Delimitação de áreas de conservação e proteção do ambiente}

O mapa das áreas de conservação e proteção do ambiente em Puerto Libertador (Mapa 6), foi obtido através do padrão de mapeamento mostrado na figura 3. Estas zonas estão compostas pelos seguintes critérios:

\section{Critérios de exclusão para a mineração:}

O artigo 34 da Lei 685 de 2001 estabeleceu as áreas que podem ser excluídos para a mineração na Colômbia e estes são definidos como aqueles em que não pode-se executar operações de mineração, uma vez que estão geograficamente definidos pelo órgão ambiental em colaboração com o autoridade de mineração. Porém, a jurisprudência do Tribunal Constitucional através da sentença C-339 de 2002, afirmou que os domínios referidos no 34 do código de mineração não 


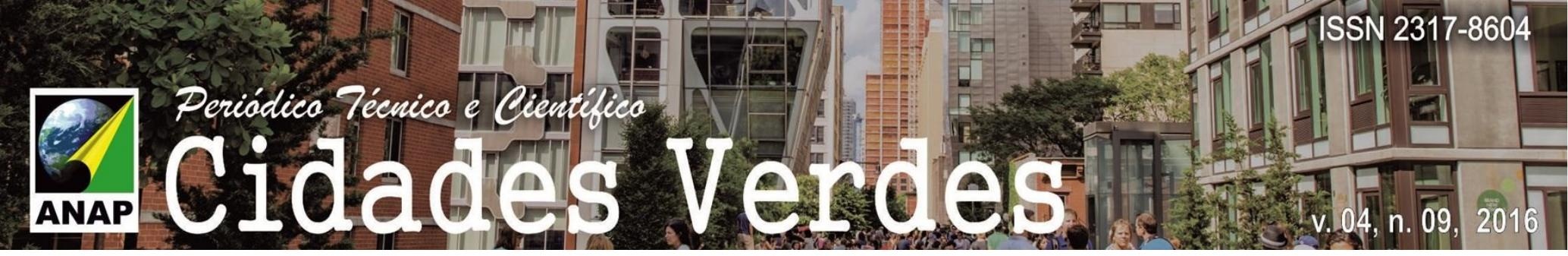

pode ser restritiva, ou seja, que pode haver outros áreas de proteção que podem ser excluídas da indústria mineira, desde que estes tenham cumprido os requisitos de declaração e de delimitação. Por esta razão, as áreas protegidas que menciona o artigo 10 do Decreto 2370 de 2010, são excluídas para a atividade extrativa. Em suma, no caso de Puerto Libertador as áreas excluídas que aplicam são:

\section{Parque Nacional Natural Paramillo (PNNP)}

PNNP faz parte do sistema de parques nacionais e de acordo com o artigo 331 do Decreto-Lei 2.811, de 1974, atividades permitidas nesta área são a conservação, recuperação e controle, pesquisa, educação, recreação e cultura. Esta área de exclusão para mineração abrange 50.426 ha do município, o que representa 30,54\% do território.

Áreas de florestais de proteção para a conservação e preservação da água (AFPPA)

No artigo 204 do Decreto 2811 de 1974 define-se que é uma área de floresta de proteção e também na mesma legislação as áreas de reserva para a proteção, conservação e preservação do meio ambiente e dos recursos naturais, sendo aplicáveis a Puerto Libertador, na categoria de conservação e preservação da água os nascentes de fontes hídricas numa área de um raio de cem (100) metros e uma faixa de 30 (trinta) metros de largura, paralela à corrente de água. Em total, estas chamadas áreas de floresta de proteção para conservação e preservação da água cobre 10.928 ha do município, o que representa 6,61\% do território. 


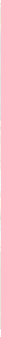

Figura 3 - Modelo cartográfico para o mapeamento das zonas de proteção e prevenção ambiental

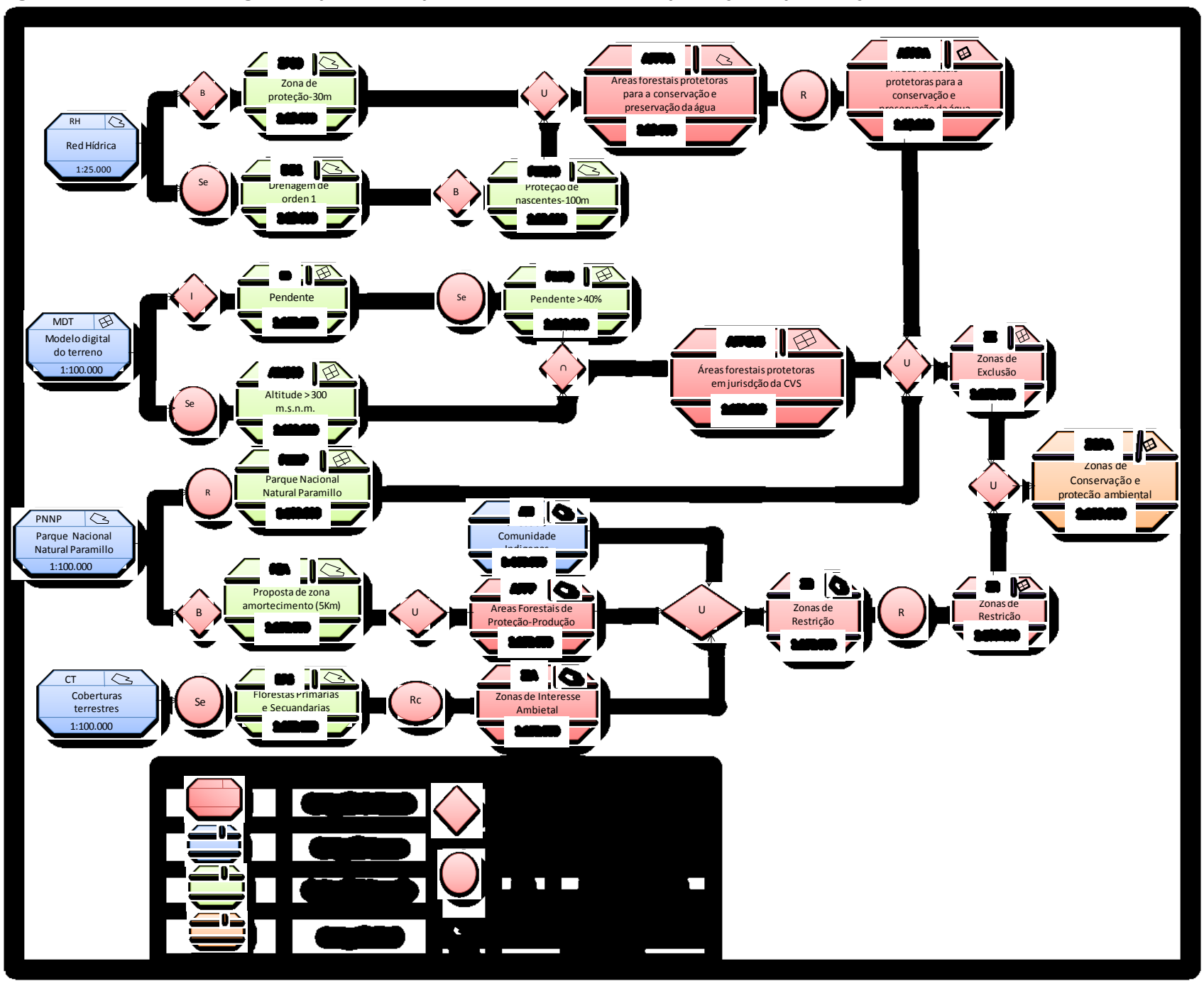

Fonte: AUTORES, 2015

Áreas florestais de proteção sob a jurisdição do CVS (CVS AFP)

Estas áreas referem-se a todas as florestas e vegetação natural, existente na área de jurisdição do CVS que está na marca de trezentos (300) metros acima do nível do mar e uma inclinação maior ou igual a 40\%. Esta zona de exclusão para a mineração tem um total de 190 ha em Puerto Libertador, o que representa $0,11 \%$ do município.

A área total excluída para a mineração em Puerto Libertador é de 61.712 ha o que corresponde a $37,4 \%$ do município. 


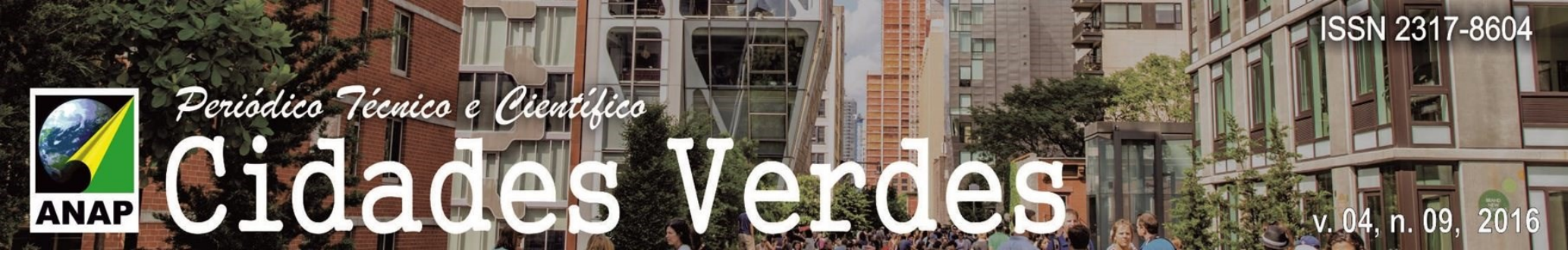

\section{Critérios de restrição para a mineração.}

O artigo 35 do Código de Mineração enuncia 8 áreas compostas por áreas e lugares onde eles podem realizar obras de exploração e mineração, autorização e restrição nesta lei estão definidos. As áreas expostas no artigo em questão que são aplicáveis em Puerto Libertador e outras áreas consideradas de mineração restritiva são:

Áreas de grupos étnicos (Comunidades Indígenas) (AGE)

A proteção da identidade cultural das comunidades indígenas encontra o seu apoio no parágrafo do artigo 330 do Constituição Política de Colômbia , além desta disposição constitucional não só apoia os direitos dos grupos étnicos no que diz respeito à mineração, mas também incluída na Lei 21, 1991 e o Código de mineração, onde neste último afirma-se que a exploração dos recursos naturais não renováveis em reservas indígenas deve ser precedida por uma consulta destas comunidades (avanço), que também tem o direito de prioridade (artigo 124 e 133 do Código de minas) para que a autoridade de mineração dá-Ihes a concessão nos campos localizados em seus territórios.

Neste sentido, pertencem a estas áreas de critério de restrição a comunidade indígena da quebrada Canaveral Embera Katio e 11 prédios não legalizados onde há assentamentos deste grupo étnico em Puerto Libertador. Assim, a área total deste critério é 3,436 ha, o que representa 2,1\% do município.

Áreas florestais de proteção - Produção (DPP):

O artigo 205 do Decreto 2.811, de 1974, define que é uma área florestal de proteção produção, no caso de Puerto Libertador, a zona de amortecimento de PNN Paramillo, está incluído nesta categoria, tal como estabelecido no projeto de acordo do EOT e serve para reduzir a perturbação causada pela atividade humana nas áreas circundantes para o parque Paramillo a fim de evitar distúrbios ou mudanças na ecologia ou a vida selvagem desta área protegida. Com base no acima exposto, a administração de PNNP estabeleceu uma distância de $5 \mathrm{~km}$ a partir do limite do parque em Puerto Libertador como uma possível zona de amortecimento, isto corresponde uma área de 30.404 ha, ou seja, $18,4 \%$ do município. É digno de nota que, embora esta área não seja regulamentada, PNNP trabalha com as autoridades ambientais regionais na declaração do buffer em cada um dos municípios em suas áreas de jurisdição, tal como estabelecido no componente de ordenamento do Plano de Gestão de PNNP.

Áreas de interesse ambiental

As áreas consideradas nesta categoria têm uma função ambiental abrangente, já que servem tanto para a regulação e fornecimento hídricos do município como para a conservação da biodiversidade e proteção da vida selvagem. 


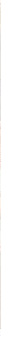

- Floresta primária: cobre uma área de 7.894 ha, o que torna-se 4,8\% do município. Estende-se na parte sul de Puerto Libertador, em grande parte do PNNP e central do distrito de Juan Jose.

Mapa 6 - Zonas de conservação e proteção ambiental de Puerto Libertador

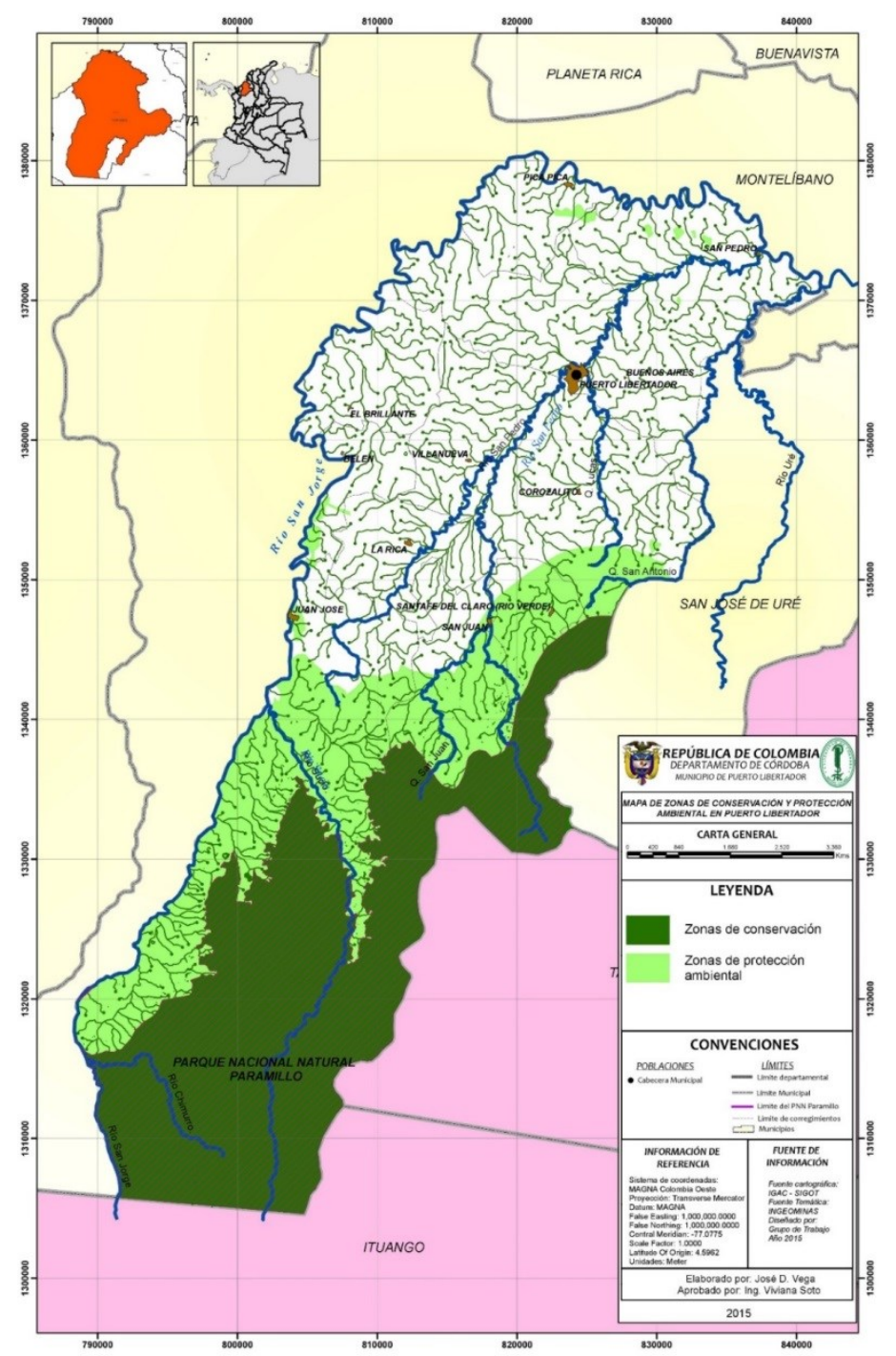

Fonte: AUTORES

- Floresta Secundária: abrange uma área de 16,310 ha, o que torna-se 9,9\% do município. Estes se desenvolvem ao sul do centro da cidade e parte de sua extensão foi interceptada.

A área total restrito para a mineração em Puerto Libertador é 30.404 ha o que representa $18,41 \%$ do município.

\section{DISCUSSÃO}




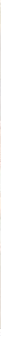

Engenharia Geológica, Universidade Politécnica de Madrid, Madrid-Espanha. Disponível em: <http://oa.upm.es/624/1/06200203.pdf

BARETTINO, D. et al. Las bases para la integración de los recursos minerales en la ordenación del territorio: el Mapa de Ordenación Minero-Ambiental. En L. Martins y P. Carrión (eds.): Integración de la Minería en la Ordenación del Territorio. ESPOL-CYTED, Guayaquil, Ecuador, pp. 139-152. 2003

COLOMBIA. Constitución Política de Colombia de 1991. Disponível em: <http://www.alcaldiabogota.gov.co/sisjur/normas/Norma1.jsp?i=4125>. Acesso em: 23 de Nov 2015.

COLOMBIA. Corte constitucional. Sentencia C-339 de 2002. Declara EXEQUIBLE los artículos 3, 4, 36, incisos 1, 2, 3 y 4 del artículo 34, literal a), c) del artículo 35 e INEXEQUIBLE parte del artículo 35 dela ley 685 e 2001. Disponível em:< http://www.corteconstitucional.gov.co/relatoria/2002/C-339-02.htm>. Acesso em: 30 de fev de 2015.

COLOMBIA. Decreto-Lei 2811 de 1974. Por el cual se dicta el Código Nacional de Recursos Naturales Renovables y de Protección al Medio Ambiente, en ejercicio de las facultades extraordinarias conferidas por la Ley 23 de 1973 y previa consulta con las comisiones designadas por las Cámaras Legislativas y el Consejo de Estado, respectivamente. Disponível em: <http://www.alcaldiabogota.gov.co/sisjur/normas/Norma1.jsp?i=1551>. Acesso em: 20 de fev de 2015.

COLOMBIA. Lei 2730, de 1 de julio de 2010. Por el cual se reglamenta el Decreto-Ley 2811 de 1974, la ley 99 de 1993, la ley 165 de 1994 y el Decreto-Ley 216 de 2003, en relación con el Sistema Nacional de Áreas Protegidas, las categorías de manejo que lo conforman y se dictan otras disposiciones. Disponível em: <https://www.minambiente.gov.co/images/normativa/decretos/2010/dec_2372_2010.pdf>. Acesso em: 5 de Fev de 2015.

COLOMBIA. Lei 685, de agosto 15 de 2001. Por la cual se expide el Código de Minas y se dictan otras disposiciones. Disponível em:< http://www.alcaldiabogota.gov.co/sisjur/normas/Norma1.jsp?i=9202 >. Acesso em: 2 de fev de 2015.

COLOMBIA. Ministerio de ambiente y desarrollo sostenible - MADS. Sinopsis Nacional de la minería aurífera artesanal y de pequeña escala: relatório. Bogotá, 2012.

CORPORACIÓN AUTÓNOMA REGIONAL DE LOS VALLES DEL SINÚ Y SAN JORGE-CVS (Colombia). Diagnóstico Ambiental de la Cuenca Hidrográfica del Río San Jorge, 2005.

CORPORACIÓN AUTÓNOMA REGIONAL DE LOS VALLES DEL SINÚ Y SAN JORGE-CVS. (Colombia).Inventario minero del municipio de Puerto Libertador, 2014

FUNDACIÓN SAN ISIDRO \& CERROMATOSO (Colombia). Sistema Integral de planeación de la subregión del alto San Jorge- SIPLAN, 2012.

HENRÍQUEZ, I. R. Y. Metodología de evaluación territorial estratégica en las actividades de interés para la minería, aplicada en SIG. [s.I.] Universidad de Santiago de Chile, 2010.

INSTITUTO GEOGRÁFICO AGUSTÍN CODAZZI -IGAC (Colombia). Estudio general de los suelos y zonificación de tierras. Departamento de Córdoba, 2009.

KEENAN, R. J. et al. Dynamics of global forest area: Results from the FAO Global Forest Resources Assessment 2015. Changes in Global Forest Resources from 1990 to 2015, v. 352, p. 9-20, jul. 2015.

MARRUGO J. e LANS E. 2006. Impacto ambiental por contaminación con níquel, mercurio y cadmio en aguas, peces y sedimentos en la cuenca del río San Jorge, en el Departamento de Córdoba. Montería, Colombia. 


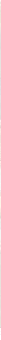

NEGRETE, I. Evaluación preliminar de la contaminación por mercurio, generados por procesos de la actividad minera ilegal de oro, en peces y sedimentos de la quebrada las Claras, en el municipio de Puerto Libertador- Córdoba. 2014. 100f. Trabalho de conclusão de curso (Bacharelado em Engenharia Ambiental) - Universidade de Córdoba-UNICOR, Montería, 2014.

ORTEGA, S. D. A. La minería y el ordenamiento territorial. Estudio de caso. Área minera, Empresa Mineros S.A., El Bagre. 2006. 131f. Dissertação (Mestrado em Meio ambiente e Desenvolvimento) -Universidade Nacional de Colômbia - UNAL, Medellín, 2006.

PARQUE NACIONAL NATURAL PARAMILLO - PNNP (Colombia). Identificación y análisis de la tenencia de la tierra, conflictos territoriales y características socioeconómicas en el resguardo quebrada cañaveral del alto San Jorge. Córdoba, 2013.

PUERTO LIBERTADOR. Alcaldía Municipal. Esquema de Ordenamiento Territorial (EOT): relatório 2005 -2017. Córdoba-Colombia, 2005.

PUERTO LIBERTADOR. Alcaldía Municipal. Plan de Desarrollo Municipal de Puerto Libertador (PDM): relatório 2012 2015. Córdoba-Colombia, 2013.

RICAURTE, L. F. Zonificación ambiental del río Putumayo: Zonificación ambiental para el ordenamiento territorial en la Amazonia Colombiana. Libro de memorias. Bogotá, CO, p. 45-57, 2001.

RODRÍGUEZ, Á. L.; LOZANO-RIVERA, P.; SIERRA-CORREA, P. C. Criterios de zonificación ambiental usando técnicas participativas y de información: estudio de caso zona costera del departamento Del atlántico. Boletín de Investigaciones Marinas y Costeras, v. 41, n. 1, p. 61-83, 2012.

SABATINI, M. et al. A quantitative method for zoning of protected areas and its spatial ecological implications. Journal of environmental management, v. 83, n. 2, p. 198-206, 2007. 